\title{
Online Business Among University Students: Benefits and Challenge and Successful Story of a Young Entrepreneur
}

\author{
Nur Aqilah Husna Rosli ${ }^{1 *}$, Mohd Khata Bin Jabor ${ }^{1}$, Mohd Amri Md Yunus ${ }^{1}$, \\ Ahmad Fuad Seman ${ }^{1}$, Hanim Zainal ${ }^{1}$ \\ ${ }^{l}$ Faculty of Social Sciences and Humanities, Universiti Teknologi Malaysia, 81310 UTM Johor Bahru, Johor. \\ *Corresponding author. Email: mkhata@utm.my
}

\begin{abstract}
The main purpose of this paper is to study about online business among university students. A review of relevant literature was used to gather the data for this study. The data obtained from review literature from various characters found from internet sources, namely journal, thesis collection, theory of entrepreneurship book collection in the library and also access information online database using a web of university. The findings of this study reveal the benefits that the university students can get when they are involved in online business such as low cost business, many marketing strategies, geographic barriers do not give many effects to the online business and information can be transferred easily and fast. However, online businesses also give challenge to the students such as the customers do not want to take risk of purchasing online products. Even though there is challenge in conducting online business, there are many university students out there take the challenge to do online businesses and become young entrepreneur because they realize the benefits of online business.
\end{abstract}

Keywords: Advantages, disadvantages, Internet, university students

\section{INTRODUCTION}

The nature of business today and the developments in information and communications technologies have required people involve in business to employ emerging technologies in order to remain competitive in the business world. According to Robert and Melody [1], the incredible growth of the Internet has given opportunities for people to involve in an online global business. In recent years online business using electronic devices and Internet has been adopted by many people to extend and improve their businesses because they realize the beneficial functions provide by the Internet. So the objective of this study reveal the benefits that the university students can get when they are involved in online business. That benefits include such

as low cost business, many marketing strategies, geographic barriers do not give many effects to the online business and information can be transferred easily and fast.

Nowadays, online business has been chosen by many people as the source of income because the availability of the Internet. The Internet changes organizations beyond the physical constraints of their traditional distribution channels and creates a worldwide online community in which small and medium sized companies can compete with large enterprises [1]. With the advantages provide by the internet, many people have started to do online business and they only use Internet as the medium of business and they can gain profits just by using their fingertips. They also do not have to do any heavy physical works because they only need to conduct and monitor the business through the internet. Furthermore, they do not have to spend time dealing with customers face-to-face because all the transactions will be done through online.

Besides that, online business is also chosen by the business people as the medium of business because many todays' customers are well-informed with the benefits of the online shopping. The customers use the Internet to buy the things that they want because it is more convenience shopping on the internet and there is no crowd of people when shopping through online Goh and Zuroni [2]. They can shopping easily and choose the items that they want to buy without any distraction from the crowd because they only buy the items by click of mouse without going out from house. Therefore, many business people are aware with this trending and they start to do online business because of the current customers' style of shopping.

\section{LITERATURE REVIEW}

Online business is very popular these days among people in Malaysia because it is very convenient. According to Beheshti and Salehi-Sangari [3], online 
business is a system that provides Internet-based electronic businesses which act as a platform to connect with customers, business partners, and suppliers through Internet. Online business is advantageous because the Internet is not only medium of communication for the sellers and customers but it is also a medium for the sellers to contact suppliers. Hence, sellers can manipulate Internet for all their business goals and purposes. They can use the internet to promote their products as well as to deal with their suppliers. They only need internet to do all the works which is time saving and more effective.

Besides that, online shopping is also defined as the process a customer buy a service or product over the internet Goh and Zuroni [2]. Customer use Internet as the platform for them to choose products they want to buy and purchase them through online banking as many business people sell products online there. In the Internet, there are many websites, blogs and other social networks that provide services or selling various products such as clothes, gadgets, accessories, food, books and many more. With the variety of the products sold by business people in the Internet, many customers are attracted to buy online products day by day. Online business is also managed to attract people's attention because people nowadays are too busy with works and some of them do not have time to go shopping for hours. With online business which provides many choice of product and only requires the customers to order through the Internet, busy people like them can purchase the things that they want from home and they do not have to trouble themselves go to the convenience store or supermarket. They only need computer, laptop or mobile phone to choose the items they want to buy and do transactions for online buying.

\section{METHODOLOGY/MATERIALS}

During conducting this research, we were referring to the past journals. When referring to the journals, we did a lot of reading and literature review to get knowledge and information about the benefits of online business to university students.

\section{RESULTS AND FINDINGS}

\subsection{Benefits of Online Business to University Students}

\subsubsection{Low Business Cost}

As marketing needed a large sum of money as a capital, hence hinder the students who are lack in financial to boost their business. It is even not an easy task to convert skills into money and made the business as a great successful once the start off was a hard. Besides that, online businesses enhance students that have lack of money to sharpen their skills in entrepreneurship because online business prepares a platform like no others in guaranteeing a business to bloom and boost. Through online business, we do not need banner, flyers and so on to attract our customer to buy our selling products. Hence, thousands of costs are saved from this aspect and these characteristics of online business really help the young students especially in managing their business.

On the other hands, if traditional business tends to hire lots of people to manage their business, contrast with online business that need only one or two persons at the same time depending on their business scale. Furthermore, this would help to maintain a low cost of human resource in a certain company and suits with the students' as a young entrepreneur as an early platform and helpful as well. In Malaysia, currently lots of university students that bravely have a start in conducting a small scale business and then turns into a bigger scale entrepreneur lead by university students. For example, lots of fashion pioneer especially in Islamic design has been conquered by the students that majorly starts their business only using online platform like Facebook, Instagram, Twitter and finally creating an empire that well-known by the entire of the world. For example, Cala Qisya boutique was actually a small business started by a young couple from UTM at the night markets only. With perseverance and determination, their sacrifice were paid off with a huge empire they have today and made them as a young millionaire as well.

Other than that, online business can help university students to start their business since they can cut off their expenses in various field including promotion, human resource, management and other utility payment. This has made online business as the first choice by young and fresh graduate students as well to involve themselves in world of business. This also claimed students that were from university tend to choose business as their first career compared to others because of ease of marketing as what happened nowadays. We can see lots of successful business started from only a small scale on the internet and developed by times and then providing lots of career chances to jobless people as well.

\subsubsection{Many Marketing Strategies}

There are many internet-based marketing strategies can be used by online sellers to sell their products and gain huge profits by only using internet. One of the marketing strategies is promoting the products through social media such as Facebook, Instagram, Twitter and many more. University students nowadays are exposed to social media and most of them have their own private social media accounts which they use to contact family and acquaintances. They can start and create their own business account through social media too which does not require them to rent a shop to sell their products. 
During selling the products through social media, they can apply many methods to attract their customers. One of the method is by creating a branded fan page site for the business Navetta et al.[4]. They need to use their own creativity to get many as many followers as they can for their fan page such as offer discounts to the early birds, conduct contests, do promotions or give their products as a present to the lucky customers. These methods are important because they will help the sellers to engage with the customers. Besides that, they also can increase the popularity of their products by conducting user-generated content promotions. This method requires the sellers to give incentive prize and encourage their customers to give feedback about why they like their products Navetta [4]. This method is able to boost their sales too since they are giving free prizes to the customers. Satisfied customers will have positive perception to the business and there are high chances for them to repeat the orders.

Besides social media, university students can also promote their business through blogs too as the marketing strategy. They can apply word-of-mouth marketing via blogs by providing their products to popular bloggers with big number of followers and requesting them to write a favorable review Navetta [4].This strategy is good because the bloggers who write good reviews about the products will be able to influence their followers to buy that products too.

The strategies and methods mentioned in the previous paragraph are simple but able to give high impacts to the customers. University students who need to get extra money by doing business can apply these strategies because they only need internet as the medium of communication and transaction with the customers. All university students are busy with assignments, projects, tests and presentations which make them unable to them to give full commitment on businesses that require them to travel or open a shop. However, that should not be an excuse for them to not to get involve in business at all. They can start online business which require less commitments and get extra pocket money to cover their expenses at the university.

\subsubsection{Reduce the effects of geographic barriers}

As we know, geographic barriers are among the challenges need to be taken into account if we are running business. Through online business, sellers and customers are able to meet to a point where everything can be traded as long as they are valuable and both parties agree under certain agreement. This is far supported by McIvor et al [5] where business can be another idea of exchanging the goods to varying degrees and geographic barriers are not a big issue here. Other than that, online business are now growing rapidly and should be able to replace traditional business. Traditional business that most of the time prioritize the goods to be safely handed in, this time, via FedEX, Gdex and other postage service prepared to help the things sold to be safe, fast and giving profits to both sides which is customer and supplier.

Through online business, things from south can be reached to the north and received by another customer even in different continents. Hence, customer possess a high power of buying and wider of choices to select certain products. This is because not only the goods sold would be received by them safely regardless of where they are staying at, payment procedure were also not a big issue for them since we are prepared with all fingertips cervices like online banking. For Malaysia, now lots of people are having personal accounts that can be managed by internet which means payments or other transactions can be eased, safe and reliable.

According to the previous paragraphs, it can be concluded that online business is a good opportunity need be grabbed by the students because this type of business does not have geographic barrier and it allows them to do marketing beyond their current living place. Moreover, students can utilize virtual platform for promoting their business Yen and Chou [5]. They can promote their products using Internet to all people around the country and use postage services to deliver their products. With great marketing, they will be able to get many customers throughout the country and gain a lot of profits. Besides that, by using all the facilities mentioned in previous paragraph, online business can helps students to low their business cost especially during the starting phase where they are having financial conflict, management and so on. Hence, this would help them promote their products even their target market were far and staying at multiple places

\subsubsection{Information can be Transferred Easily and Fast.}

The other benefits of online business to the university students is it can transfer information fast and efficiently. Sellers can provide timely information to the customers because of the ability of instant communication Lane [7]. Since university students are packed with classes and works, online business enables them to promote and update about their products within short amount of time through the screen of the computer or smartphone only. They do not have to paste posters on notice boards or distribute flyers to the potential customers.

According to the Isaac [8], internet enables sellers to do better customer services and quicker responses. Online sellers are able to do the so because since internet is always available 24 hours a day and 7 days per week. The sellers are able to do a fast reply to the customers because they are communicating through the internet and they also can reply to the customers' orders at any time they want because usually online sellers do not have office hour. Therefore, university students are suitable to do online business since they can reply to their customers at any time. They also can 
give quick responses after they finish their class or finish doing assignments.

\subsection{Challenges of Online Business to University Students}

The challenge might be faced by online business people is some of the customer do not want to take risk by purchasing online products. Customers perceive that risk is associated to trustworthiness and likelihood of system failure Walker et al. [9]. Perceived risk can cause customers to refuse to accept new technology-based services delivery Rotchanakitumnuai and Mark [10]. They feel lack of confidence to trust the sellers that they have not meet in real world. Moreover, they need to transfer the money through online transaction and the tendency that they might be cheated by the sellers is high.

Besides that, customers are also worried that technology-based service delivery systems will not work as expected, and lack assurance that issues can be settled quickly Walker et al. [9]. Some of the customers are bothered with the possibilities of the products are not delivered to them as planned and agreed due to unexpected issues or lack of responsibilities from the sellers. They might worry about the sellers do not do the postage delivery as planned and they also might worry that there is something bad happened such as the item purchased is broken during the delivery. Hence, they tend to feel unsure and do not trust online products because of these issues.

University students who conduct online business will be unable to attract such customers because they have trust issues and do not want to take the risks of buying online products. This might be a challenge for them in order to find as many customers as they can. They need to know the best strategies to find customers in order to overcome problems like this.

\section{CONCLUSION}

As a conclusion, entrepreneurship skills are important in real life to survive in this challenging world. To be more precise, it is a very significant step taken by tertiary level education parties to include entrepreneur subject to be learned by all university students. This is because it is useful to be applied and practiced in the future. Hence, we need to be more productive and resourceful in inculcating entrepreneurship skills among young and fresh graduate especially. Even this issue had not been emphasize during early educational level, hopefully we would still produce lots of young and successful online entrepreneur that would boost Malaysia economy towards Vision 2020.

\section{REFERENCES}

[1] Melody, Y. K. and Robert, T. C. (2011). A framework for analyzing the potential benefits of internet marketing. Journal of Electronic Commerce Research. 2(4). 157-163.

[2] Zuroni Md Jusoh and Goh, H. L. (2012). Factors influencing consumers' attitude towards ecommerce purchases through online shopping. International Journal of Humanities and Social Science. 2(4). 223-230.

[3] Behesti, H. M. and Salehi-Sangari, E. (2006).The benefits of e-business adoption: an empirical study of Swedish SMEs. Service Business. 233-245.

[4] Navetta, D., Merrill, T., Latham, K. and Santalesa, R. (2011, April). Social media: The business benefits may be enormous, but can the risks - reputational, legal, operational - be mitigated?. Retrieved May 10, 2016, from http://www.acegroup.com/usmedia.pdf en/assets/ace-progress-report-social-

[5] McIvor, R., P. Hamphreys, and G. Huang (2000). "Electronic Commerce: Re-engineering the BuyerSupplier Interface," Business Process Management Journal, Vol. 6, No. 2:122- 138.

[6] Yen, D.C. and D.C. Chou (2001). Intranets for Organizational Innovation. Information Management and Computing Security. (9)(2). 80-87.

[7] Lane, A., "Success in sight... or site?" Australian Accountant, Vol.66, No.10:22-25, Nov 1996.

[8] Isaac, P., "Electronic commerce benefits is frictionless trading," New Zealand Manufacturer, pp.38-39, Feb 1998.

[9] Walker, R.H., M. Craig-Lees, R. Hecker and H. Francis, "Technology-Enabled Service Delivery: An Investigation of Reasons Affecting Customer Adoption and Rejection," International Journal of Service Industry Management, (13)(1) 106-120.

[10] Rotchanakitumnuai, S. and Speece, M. (2004). Corporate customer perspectives on business value of thai internet banking. Corporate Customer Perspectives on Business Value of Thai Internet Banking. 5(4). 270-286. 